Supporting Information

\title{
Microdomain Orientation of Star-Shaped Block Copolymer thin film depending on Molecular Weight
}

So Yeong Park, Chungryong Choi, Kyu Seong Lee, Eunseol Kim, Seonghyeon Ahn, Jaeyong Lee and Jin Kon Kim*

†National Creative Research Initiative Center for Smart Block Copolymers, Department of Chemical Engineering, Pohang University of Science and Technology, Pohang, Kyungbuk 37673, Republic of Korea

* To whom correspondence should be addressed (jkkim@ postech.ac.kr), 
S1. Synthetic route of (PMMA-b-PS)6
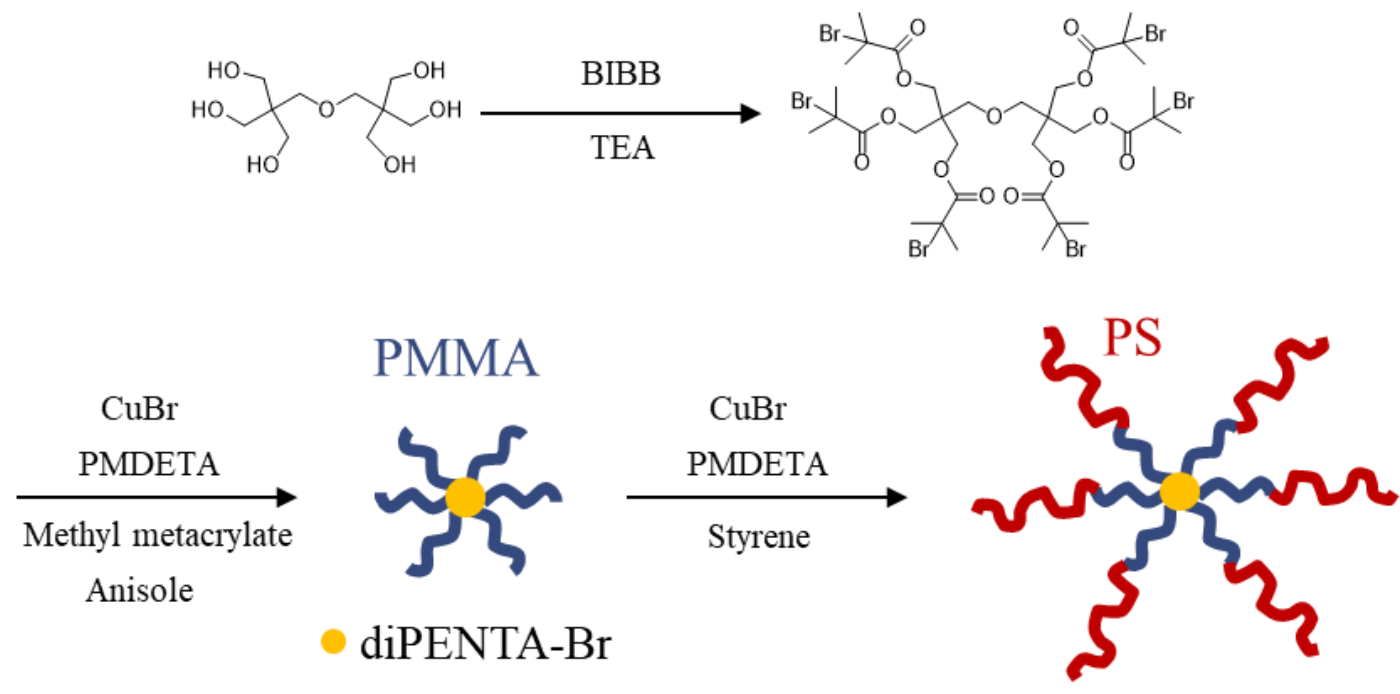

Figure S1. Synthetic route of star-shaped (PMMA- $b$-PS)6 


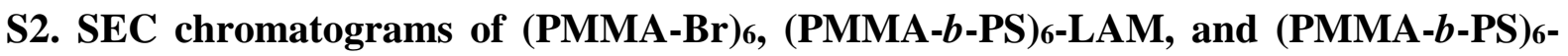
CYL

Figures S2-4 give SEC traces of (PMMA-Br) 6 , CUT_(PMMA-Br) 6 , (PMMA- $b-\mathrm{PS})_{6}$ and linear PMMA- $b$-PS consisting of (PMMA- $b$-PS) ${ }_{6}$ by cutting the ester linking group [CUT_(PMMA$b$-PS)6]. All samples show a single peak and narrow PDI. SEC traces of all CUT_(PMMA- $b$ PS) 6 do not have any peak corresponding to CUT_(PMMA-Br)6 (Figures S3-S4). Thus, all of the second PS block were attached to all of six reacting Br groups in (PMMA-Br)6. The molecular characteristics of CUT_(PMMA-Br) ${ }_{6}$ and CUT_(PMMA- $b$-PS) 6 are given in Table S1.
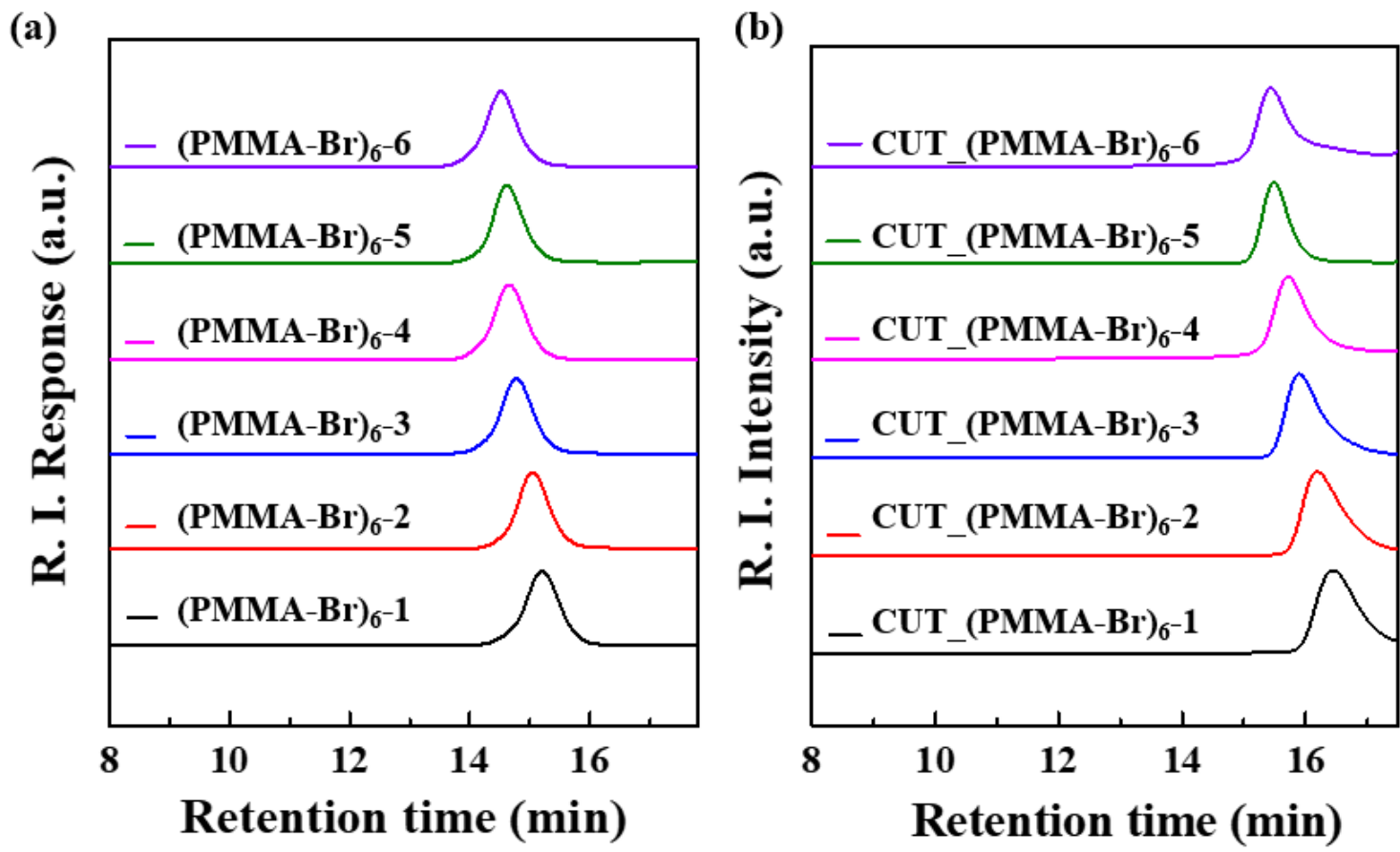

Figure S2. SEC traces of (a) 6-arm star-shaped PMMA homopolymers [(PMMA-Br) 6 , (b) linear PMMA consisting of (PMMA-Br) 6 by cutting the ester group linking diPENTA-Br and PMMA block [CUT_(PMMA-Br)6]. 

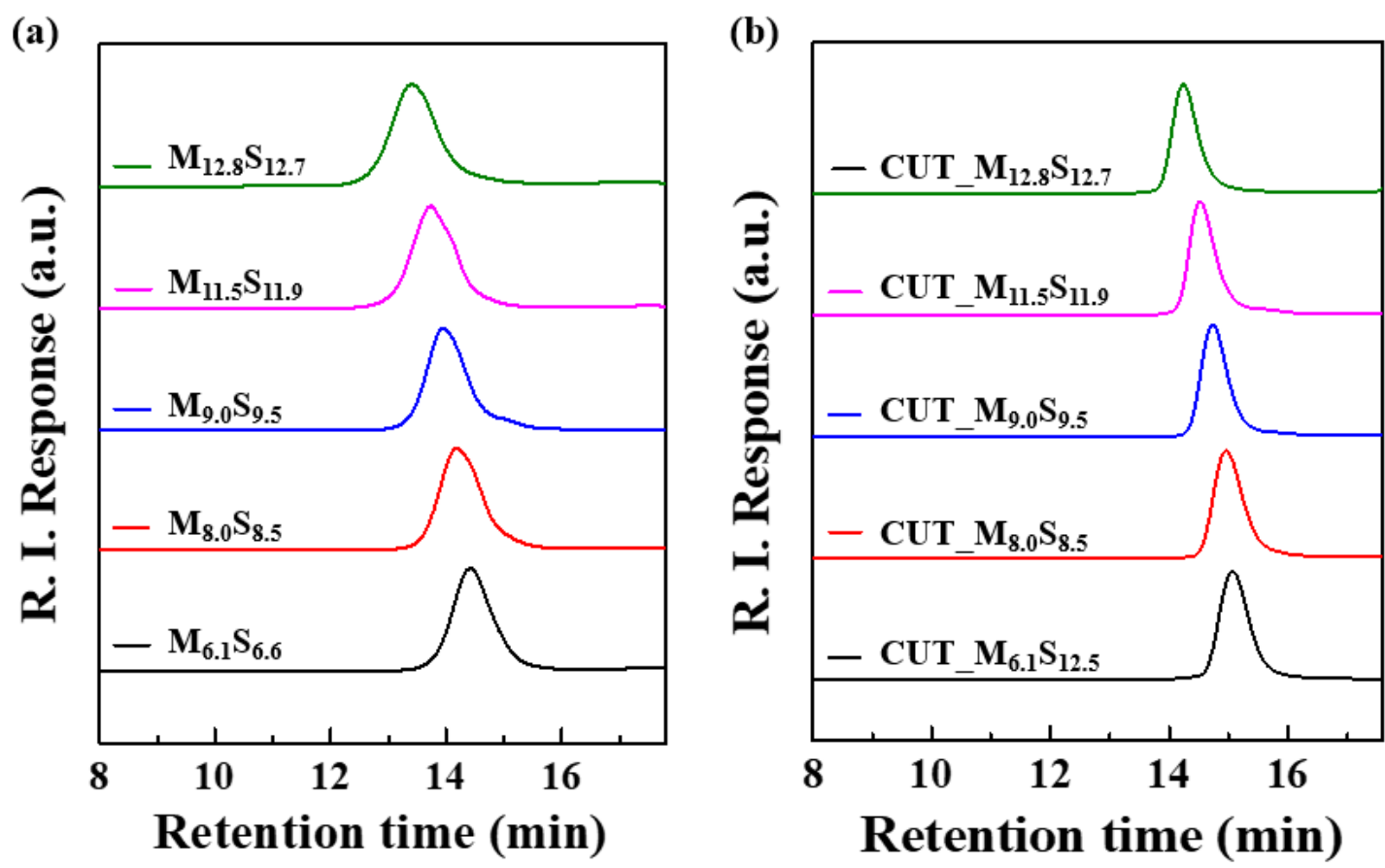

Figure S3. SEC traces of (a) 6-arm star-shaped (PMMA- $b$-PS) 6 -LAM, (b) linear PMMA- $b$-PS consisting of (PMMA- $b$-PS) ${ }_{6}$-LAM by cutting the ester linking group [CUT_(PMMA- $b$-PS) 6 ].
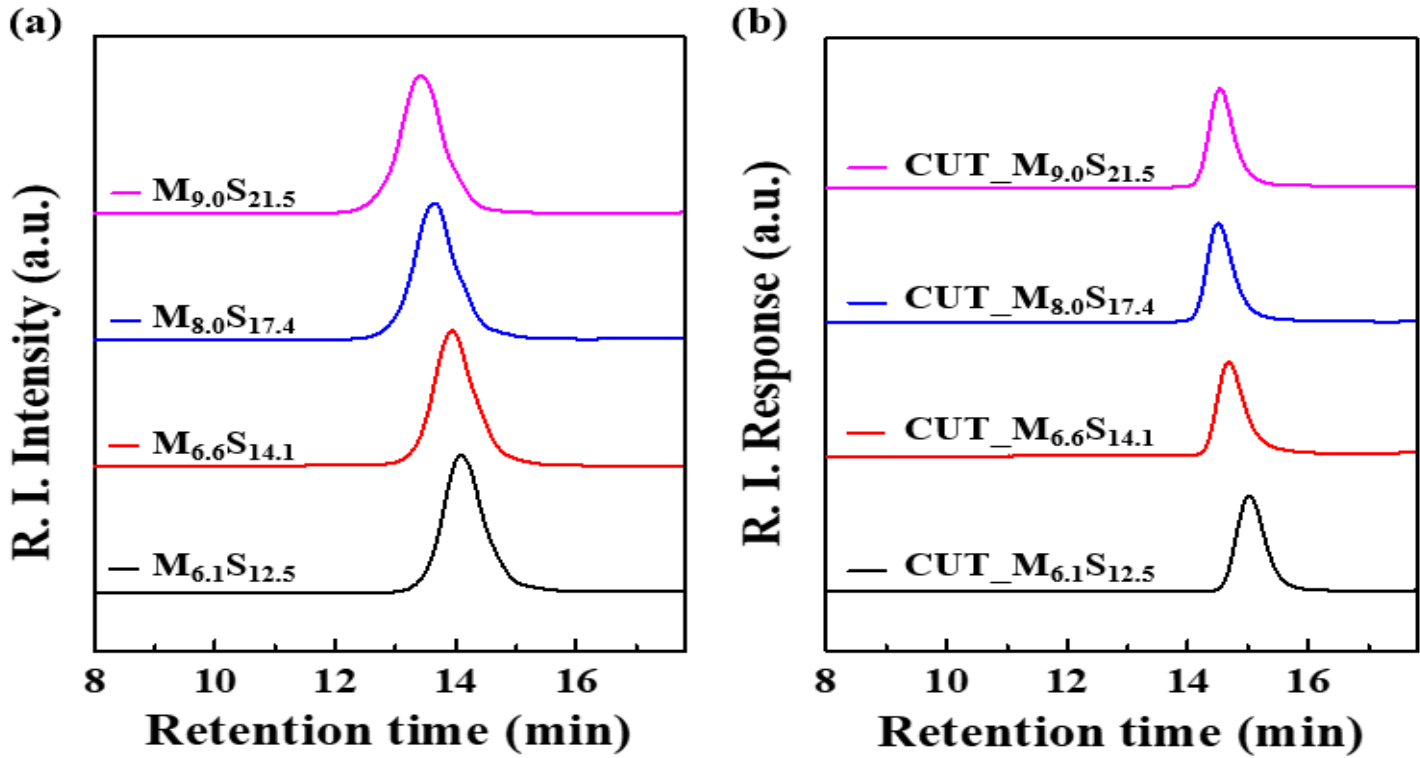

Figure S4. SEC traces of (a) 6-arm star-shaped (PMMA- $b$-PS) 6 -CYL, (b) linear PMMA- $b$-PS consisting of (PMMA- $b$-PS $)_{6}-$ CYL by cutting the ester linking group [CUT_(PMMA- $b$-PS) 6 ]. 
Table S1. Molecular characteristics of polymers employed in this study

\begin{tabular}{|c|c|c|c|}
\hline Sample code & $\mathbf{M}_{\mathbf{n}, \mathbf{S E C}^{\mathrm{a}}}$ & $M_{w} / M_{n}^{a}$ & Core PMMA \\
\hline CUT_(PMMA-Br) $)_{6}-1$ & 6100 & 1.10 & \\
\hline CUT_(PMMA-Br)6-2 & 6600 & 1.11 & \\
\hline CUT_(PMMA-Br)6-3 & 8000 & 1.08 & \\
\hline CUT_(PMMA-Br) $)_{6}-4$ & 9000 & 1.11 & \\
\hline CUT_(PMMA-Br)6-5 & 11500 & 1.06 & \\
\hline CUT_(PMMA-Br)6-6 & 12800 & 1.09 & \\
\hline CUT_M ${ }_{6.1} \mathrm{~S}_{6.6}$ & 14500 & 1.07 & $(\mathrm{PMMA}-\mathrm{Br})_{6}-1$ \\
\hline CUT_M ${ }_{8.0} \mathrm{~S}_{8.5}$ & 19400 & 1.08 & $(\mathrm{PMMA}-\mathrm{Br})_{6}-3$ \\
\hline CUT_M ${ }_{9.0} \mathrm{~S}_{9.5}$ & 21500 & 1.05 & $(\mathrm{PMMA}-\mathrm{Br})_{6}-4$ \\
\hline $\mathrm{CUT}_{-} \mathrm{M}_{11.5} \mathrm{~S}_{11.9}$ & 26600 & 1.05 & $(\mathrm{PMMA}-\mathrm{Br})_{6}-5$ \\
\hline $\mathrm{CUT}_{-} \mathrm{M}_{12.8} \mathrm{~S}_{12.7}$ & 29400 & 1.06 & $(\mathrm{PMMA}-\mathrm{Br})_{6}-6$ \\
\hline CUT_M $6.1 S_{12.5}$ & 21700 & 1.07 & $(\mathrm{PMMA}-\mathrm{Br})_{6}-1$ \\
\hline CUT_M $6.6 \mathrm{~S}_{14.1}$ & 23600 & 1.06 & $(\mathrm{PMMA}-\mathrm{Br})_{6}-2$ \\
\hline CUT_M ${ }_{8.0} \mathrm{~S}_{17.4}$ & 28800 & 1.06 & $(\mathrm{PMMA}-\mathrm{Br})_{6}-3$ \\
\hline CUT_M ${ }_{9.0} \mathrm{~S}_{21.5}$ & 35800 & 1.06 & $(\mathrm{PMMA}-\mathrm{Br})_{6}-4$ \\
\hline
\end{tabular}

a Determined by SEC based on PS standards. 


\section{S3. Phase Behavior of STAR-LAM and STAR-CYL with various molecular weights}

Figure S5 shows temperature dependence of depolarized light scattering intensity of STARLAM. We also prepared $\mathrm{M}_{6.7} \mathrm{~S}_{7.3}$ and $\mathrm{M}_{7.4} \mathrm{~S}_{7.9}$ by blending $25 / 75$ and $75 / 25$ (wt/wt) of $\mathrm{M}_{6.1} \mathrm{~S}_{6.6} / \mathrm{M}_{8.0} \mathrm{~S}_{8.5}$, respectively. It is clearly seen in Figure S5 that $\mathrm{M}_{6.7} \mathrm{~S}_{7.3}$ is in the disordered state over the entire temperature (up to $270{ }^{\circ} \mathrm{C}$ ). $\mathrm{M}_{7.4} \mathrm{~S}_{7.9}$ and $\mathrm{M}_{8.0} \mathrm{~S}_{8.5}$ have ODT at $215{ }^{\circ} \mathrm{C}$ and $227{ }^{\circ} \mathrm{C}$, respectively. On the other hand, $\mathrm{M}_{9.0} \mathrm{~S}_{9.5}$ is fully ordered over the entire experimental temperatures.

Figure S6a gives SAXS profiles for $\mathrm{M}_{8.0} \mathrm{~S}_{8.5}$ at various temperatures. The first peak becomes broad at $230^{\circ} \mathrm{C}$, corresponding to the disordered state. Figure S6b shows plots of $1 / \mathrm{I}\left(\mathrm{q}^{*}\right)$ and full width at half maximum (FWHM) versus $1 / \mathrm{T}$, from which the $\mathrm{T}_{\mathrm{ODT}}$ of $\mathrm{M}_{8.0} \mathrm{~S}_{8.5 \mathrm{Was}}$ determined to be $227 \pm 5^{\circ} \mathrm{C}$.

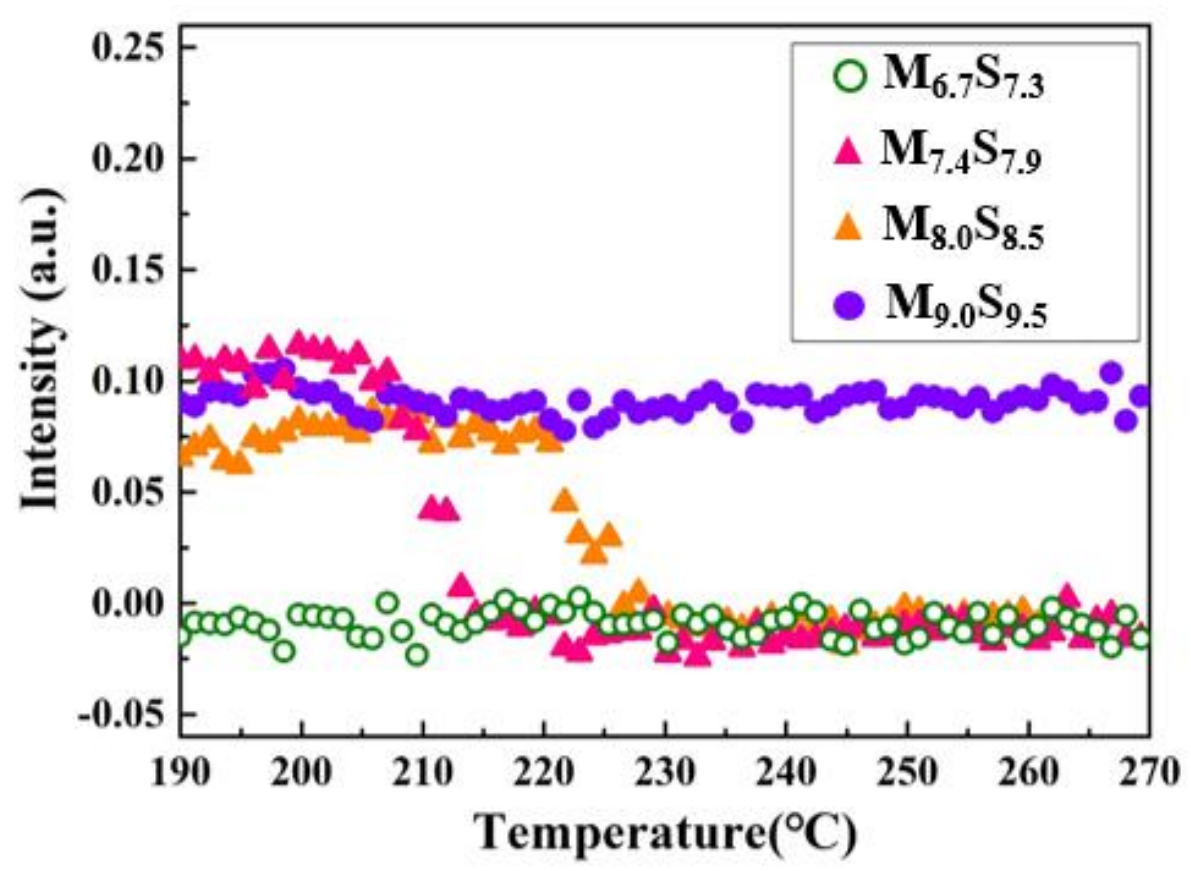

Figure S5. Temperature dependence of depolarized light scattering intensity STAR-LAM with various molecular weights. 
(a)

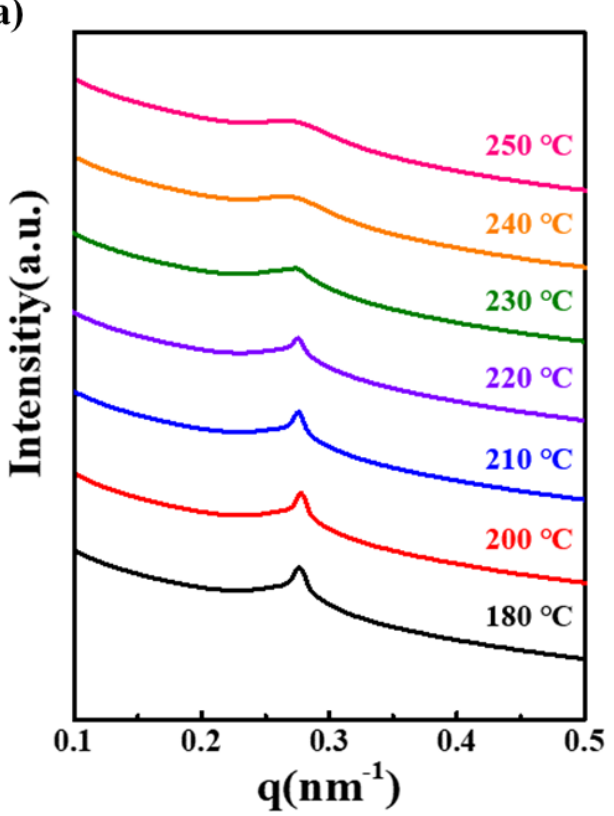

(b)

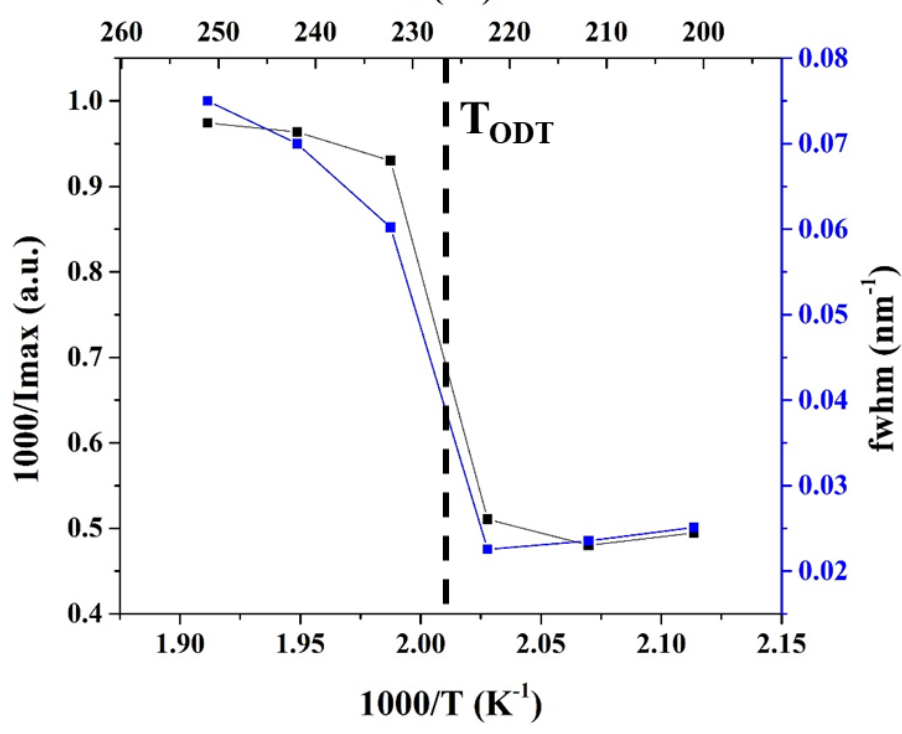

Figure S6. SAXS profiles at various temperatures and plots of 1/I( $\left.\mathrm{q}^{*}\right)$ and FWHM versus 1/T for $\mathrm{M}_{8.0} \mathrm{~S}_{8.5}$.

Figure S7 shows temperature dependence of depolarized light scattering intensity of STARCYL with three different molecular weights. $\mathrm{M}_{6.1} \mathrm{~S}_{12.5}$ are in the disordered state over the entire temperature. $\mathrm{M}_{6.6} \mathrm{~S}_{14.1}$ has ODT at $247{ }^{\circ} \mathrm{C}$. On the other hand, $\mathrm{M}_{8.0} \mathrm{~S}_{17.4}$ showed fully ordered state up to $270{ }^{\circ} \mathrm{C}$. Figure S8a gives SAXS profiles for $\mathrm{M}_{6.6} \mathrm{~S}_{14.1}$ at various temperatures. The first peak become broad at $250^{\circ} \mathrm{C}$, corresponding to the disordered state. Figure S8b shows plots of $1 / \mathrm{I}\left(\mathrm{q}^{*}\right)$ and full width at half maximum (FWHM) versus $1 / \mathrm{T}$, from which the TODT of $\mathrm{M}_{6.6} \mathrm{~S}_{14.1}$ was determined to be $247 \pm 5{ }^{\circ} \mathrm{C}$. 


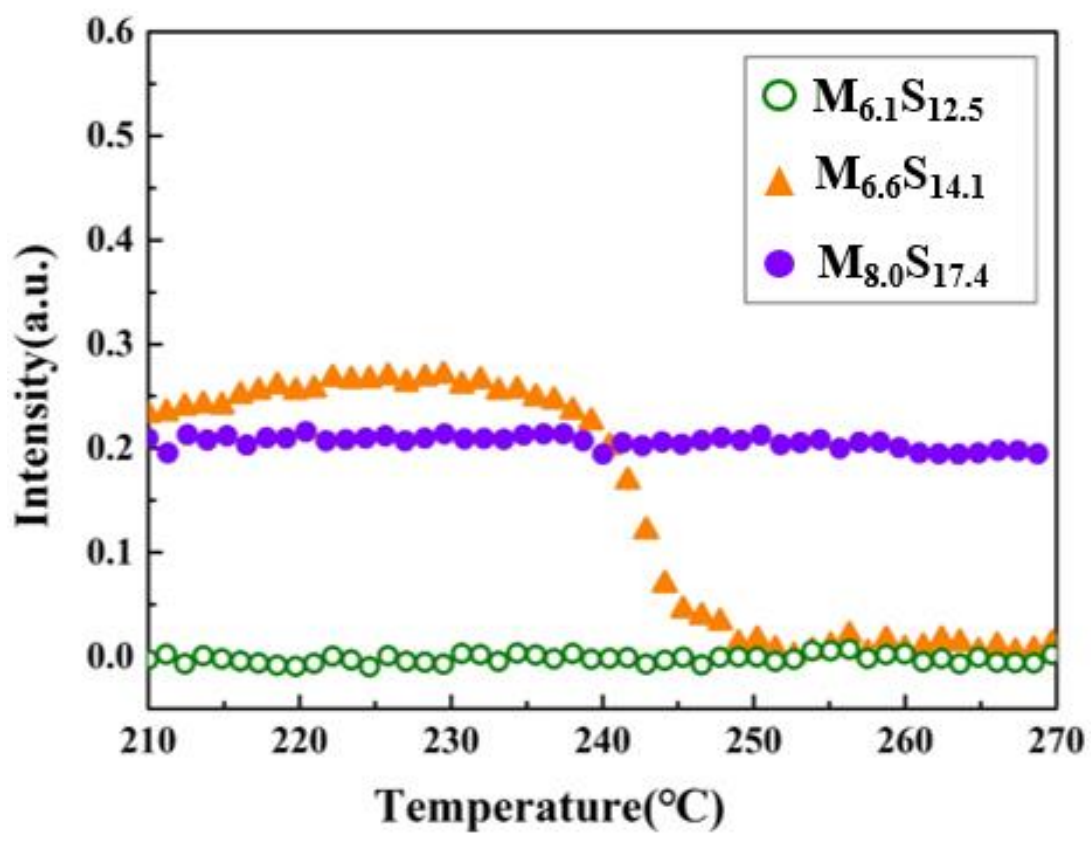

Figure S7. Temperature dependence of depolarized light scattering intensity of STAR-CYL with three different molecular weights.

(a)

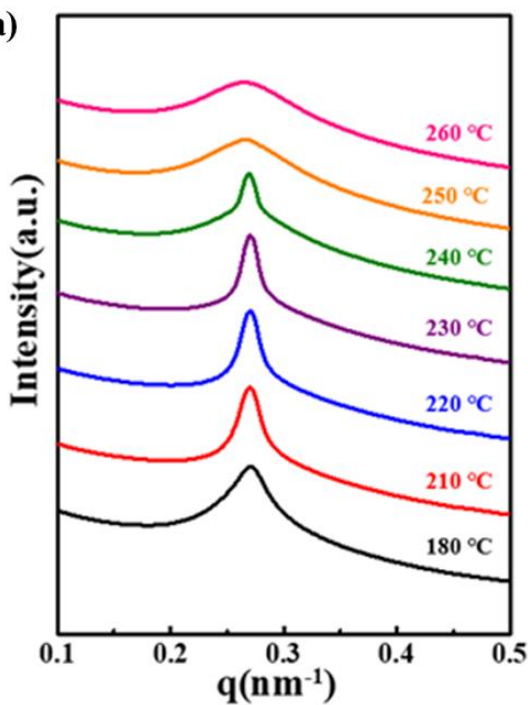

(b) $\quad \mathrm{T}\left({ }^{\circ} \mathrm{C}\right)$

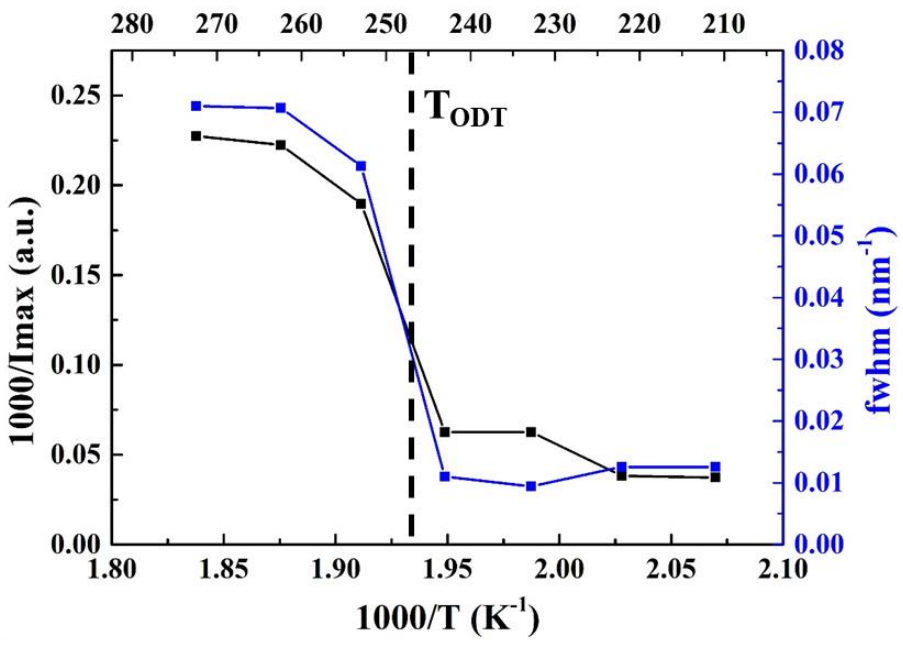

Figure S8. SAXS profiles at various temperatures and plots of $1 / \mathrm{I}\left(\mathrm{q}^{*}\right)$ and $\mathrm{FWHM}$ versus $1 / \mathrm{T}$ for $\mathrm{M}_{6.6} \mathrm{~S}_{14.1}$. 
S4. Height AFM image of $\mathrm{M}_{8.0} \mathrm{~S}_{8.5}$ and $\mathrm{M}_{10.2} \mathrm{~S}_{10.7}$ thin films

(a)

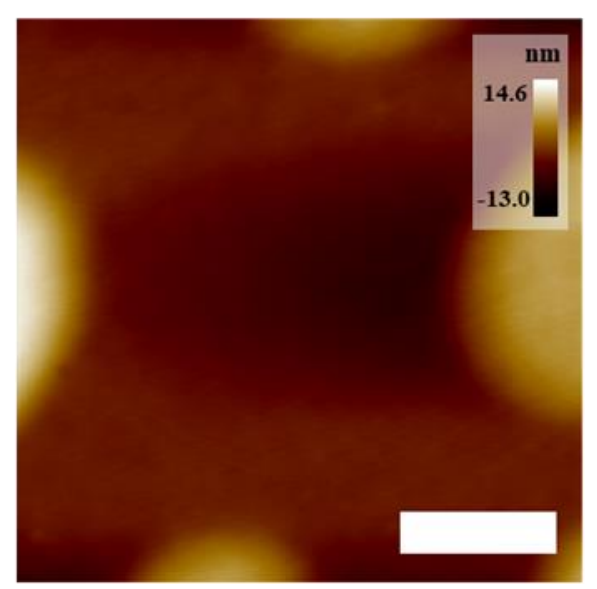

(b)

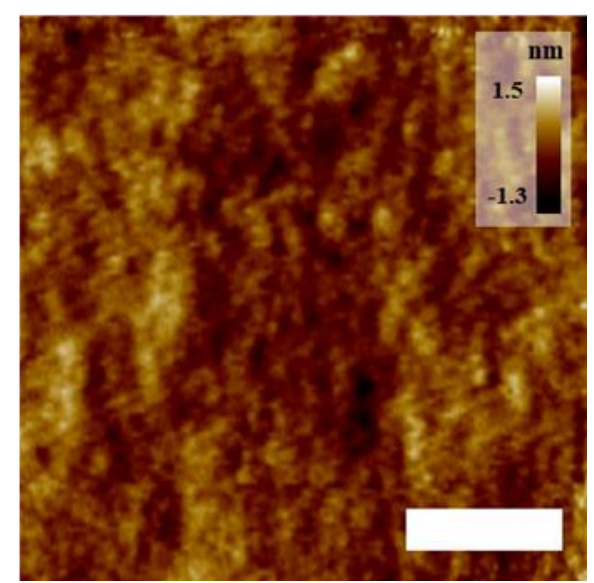

Figure S9. Height AFM images of (a) $\mathrm{M}_{8.0} \mathrm{~S}_{8.5}$ at a thickness of $26.0 \mathrm{~nm}\left(1 \mathrm{~L}_{0}\right)$ and (b) $\mathrm{M}_{10.2} \mathrm{~S}_{10.7}$ at a thickness of $47.9 \mathrm{~nm}\left(1.5 \mathrm{~L}_{0}\right)$. The scale bar is $550 \mathrm{~nm} . \mathrm{M}_{10.2} \mathrm{~S}_{10.7}$ was prepared by blending $50 / 50(w t / w t)$ of $\mathrm{M}_{9.0} \mathrm{~S}_{9.5}$ and $\mathrm{M}_{11.5} \mathrm{~S}_{11.9}$.

S5. Phase AFM image of M11.5S11.9 with different film thicknesses
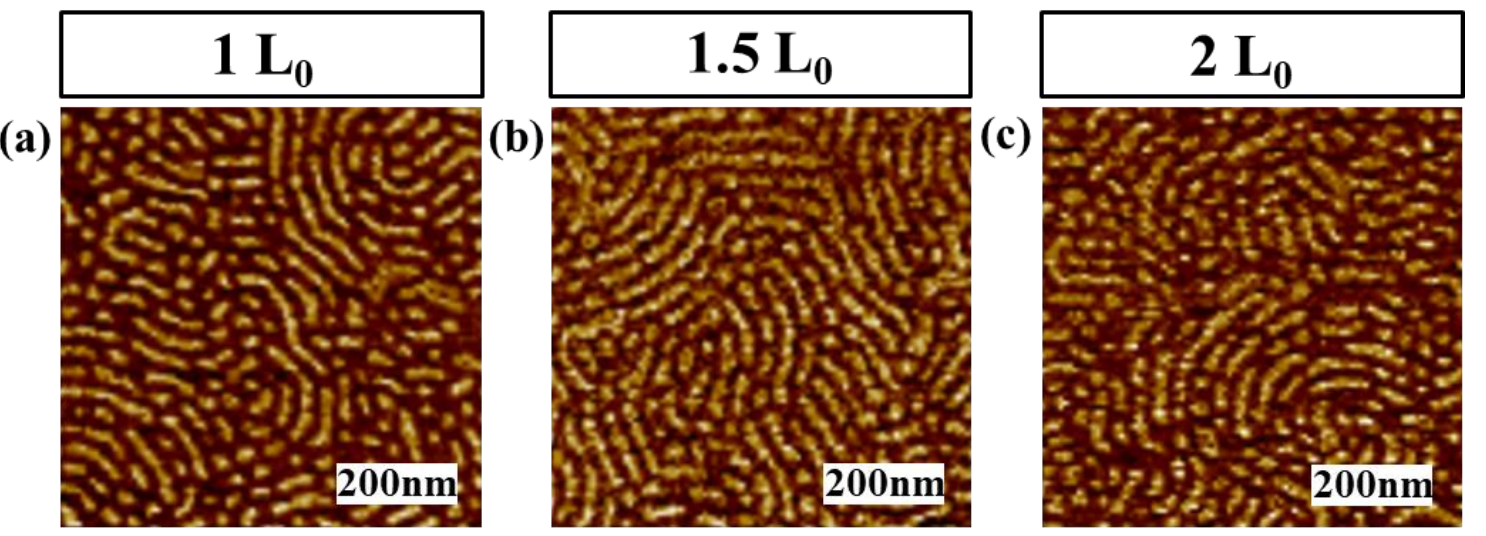

(c)

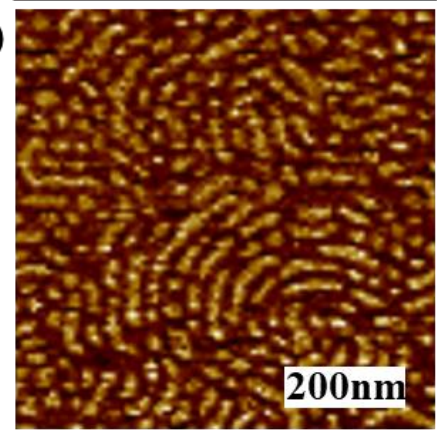

Figure S10. Phase contrast AFM images of $\mathrm{M}_{11.5} \mathrm{~S}_{11.9}$ thin films on a silicon substrate with a native oxide with different film thicknesses (a. $33.3 \mathrm{~nm}$, b. $50.2 \mathrm{~nm}$, c. $68.1 \mathrm{~nm}$ ). 


\section{S6. Water contact angle of diverse substrates}
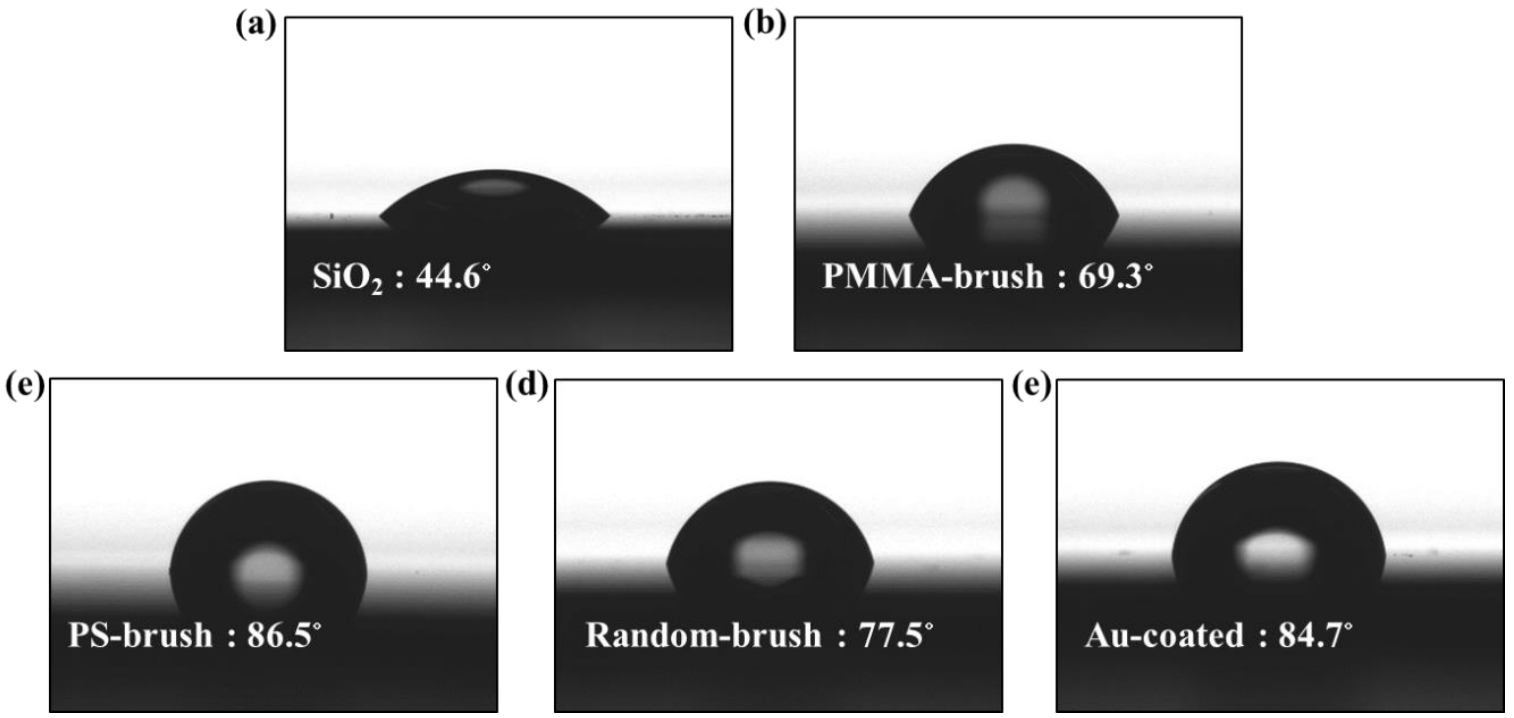

Figure S11. Water contact angles of diverse substrates: (a) a silicon substrate with a native oxide, (b) PMMA-brush on a silicon substrate, (c) PS-brush on a silicon substrate, (d) Random brush on a silicon substrate, (e) Au-coated silicon substrate. 


\section{S7. Phase contrast AFM images of $\mathrm{M}_{8.0} \mathrm{~S}_{17.4}$ and $\mathrm{M}_{9.0} \mathrm{~S}_{21.5}$ thin films on Au-coated silicon}

substrate

(a)

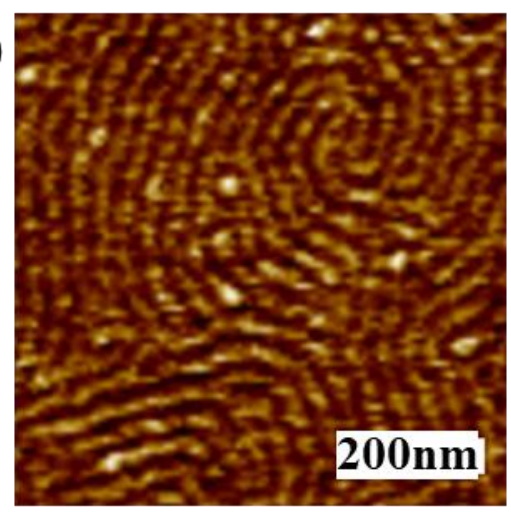

(b)

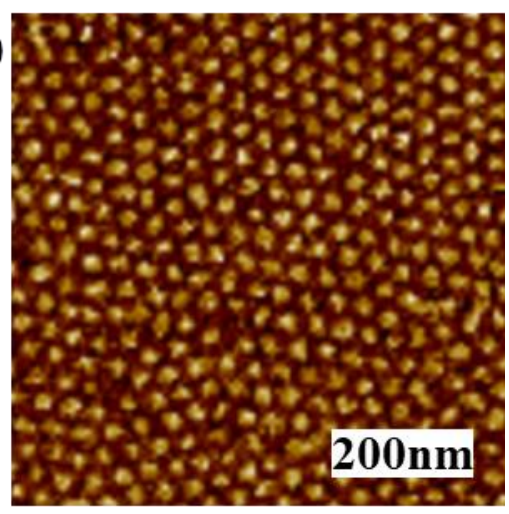

Figure S12. Phase contrast AFM images of (a) $\mathrm{M}_{8.0} \mathrm{~S}_{17.4}$ and (b) $\mathrm{M}_{9.0} \mathrm{~S}_{21.5}$ thin films on Aucoated substrate. The film thickness of $\mathrm{M}_{8.0} \mathrm{~S}_{17.4}$ and $\mathrm{M}_{9.0} \mathrm{~S}_{21.5}$ is $29.4 \mathrm{~nm}\left(1 \mathrm{~L}_{0}\right)$ and $31.7 \mathrm{~nm}(1$ $\left.\mathrm{L}_{0}\right)$, respectively.

Figure S12 gives phase contrast AFM images of $\mathrm{M}_{8.0} \mathrm{~S}_{17.4}$ and $\mathrm{M}_{9.0} \mathrm{~S}_{21.5}$ thin films on an Aucoated silicon substrate. Au was coated by thermal evaporation and the thickness was $44 \mathrm{~nm}$. $\mathrm{M}_{8.0} \mathrm{~S}_{17.4}$ thin film showed parallel oriented cylinders without showing holes (or islands). This indicates that the film thickness of $1 \mathrm{~L}_{0}$ matches with the commensurability, because the contact angle $\left(84.7^{\circ}\right)$ of Au-coated silicon oxide is close to that $\left(86.5^{\circ}\right)$ of a PS-brush substrate, as shown in Figure $\mathrm{S} 11$. On the other hand, $\mathrm{M}_{9.0} \mathrm{~S}_{21.5}$ with large $\mathrm{M}$ showed vertically oriented cylinders. 


\section{S8. FE-SEM and cross-sectional TEM images of (PMMA-b-PS)6-LAM}

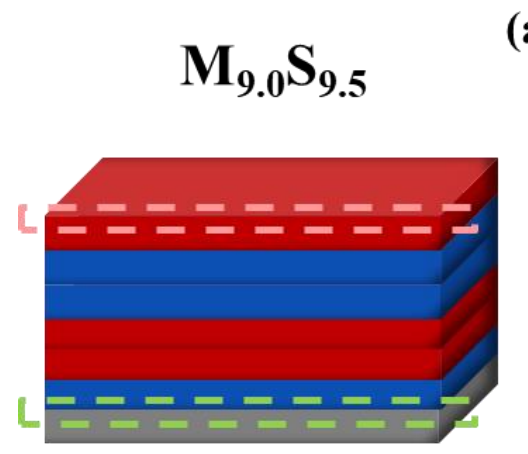

(a)

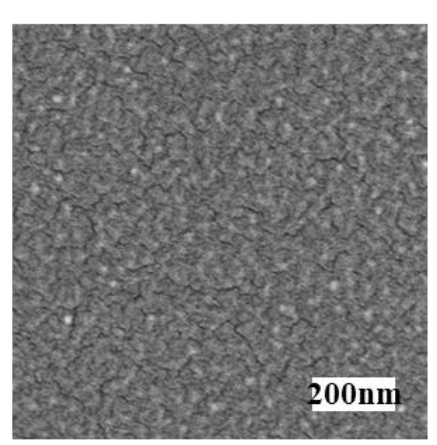

(c)

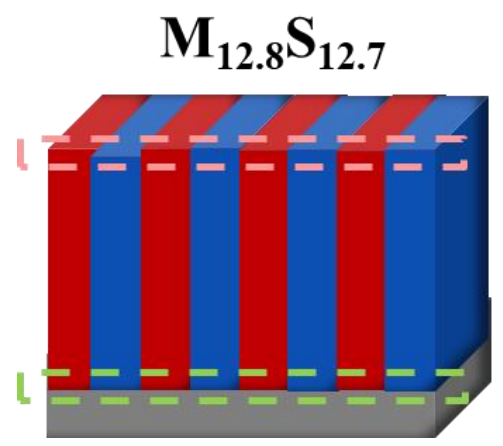

(b)

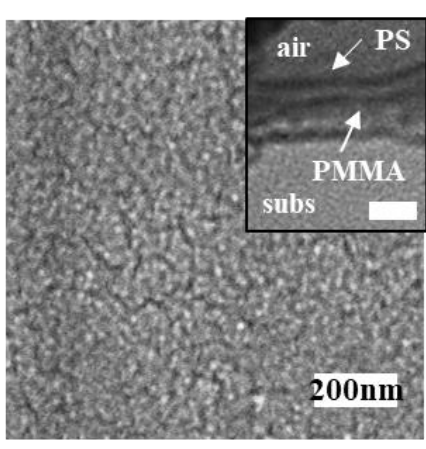

(d)

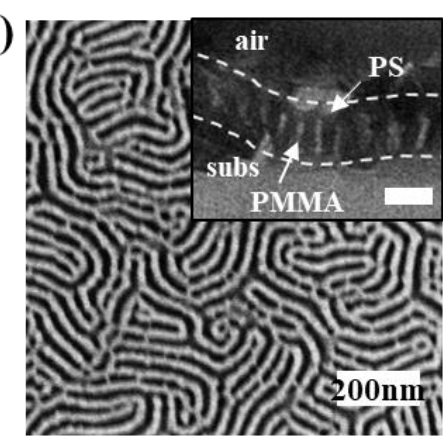

Figure S13. FE-SEM images of top surface (a, c) and bottom surface (b, d) of $\mathrm{M}_{9.0} \mathrm{~S}_{9.5}$ (upper panels) and $\mathrm{M}_{12.8} \mathrm{~S}_{12.7}$ (lower panels) thin film after removal of PMMA block by RIE etching. The film thickness of $\mathrm{M}_{9.0} \mathrm{~S}_{9.5}$ and $\mathrm{M}_{12.8} \mathrm{~S}_{12.7}$ is $.46 .0 \mathrm{~nm}\left(1.5 \mathrm{~L}_{0}\right)$ and $72 \mathrm{~nm}\left(2 \mathrm{~L}_{0}\right)$, respectively. Inset of (b) and (d) are cross-sectional TEM images for $\mathrm{M}_{9.0} \mathrm{~S}_{9.5}$ thin film and $\mathrm{M}_{12.8} \mathrm{~S}_{12.7}$. The scale bars in the inset of (b) and (d) is $50 \mathrm{~nm}$, respectively..

To confirm the bottom side of the thin film, the thin film was removed from $\mathrm{SiO}_{2}$ substrate by using $10 \%$ HF solution. The backside film was placed on the top of another silicon substrate. Then, PMMA block was removed by RIE etching. Figure S13a and S13b show featureless images, indicating that $\mathrm{M}_{9.0} \mathrm{~S}_{9.5}$ thin film exhibits parallel oriented lamellae. This is confirmed by cross-sectional TEM image given in the inset of Figure S13b. The parallel orientation of PMMA (bright region) and PS (dark region) lamellae are clearly seen through the entire film thickness (Inset of Figure S13b). Here, PMMA is located at the substrate and PS is located at air side. Namely, parallel oriented lamellae are well formed through the entire film thickness. 
On the other hand, when the molecular weight increases, vertically oriented PS lamellae are observed in SEM images (Figure S13c and S13d) as well as the cross-sectional TEM image (inset of Figure S13d). This indicates that vertically oriented lamellae are well formed through the entire film thickness. 